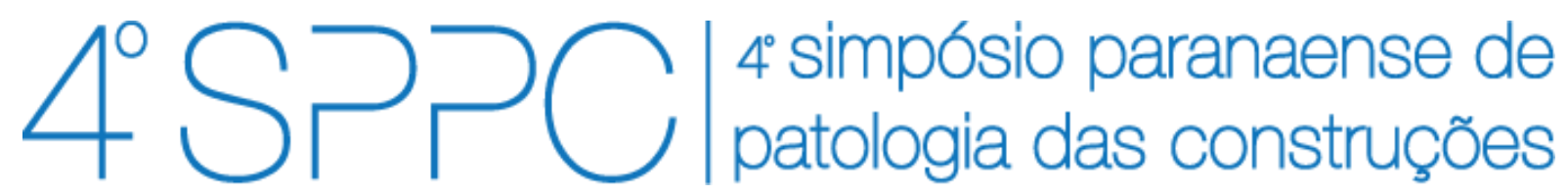

ISSN 2526-7248 artigo n. 4SPPC154, pp. 491-503, 2019

\title{
Fissuras e Trincas em Sistema de Alvenaria de Vedação: Estudo de caso em unidade residencial
}

\author{
Nacimento, Raissa Soares ${ }^{1}$; Cicuto, Bárbara Gonçalves Pereira ${ }^{2}$ \\ ${ }^{1}$ Engenheira Civil mestranda, Universidade Federal do Paraná (UFPR), \\ raissa_soares12@hotmail.com \\ 2 Engenheira Civil mestranda, Universidade Federal do Paraná (UFPR), \\ barbara.cicuto.pereira@gmail.com
}

\begin{abstract}
Resumo: O surgimento de fissuras e trincas em sistemas de alvenaria é uma das principais manifestações patológicas que afetam as construções civis. O objetivo do presente trabalho é apresentar um estudo de caso realizado em uma unidade residencial, na qual foram identificadas fissuras e trincas nos sistemas de vedação em alvenaria de bloco cerâmico, a fim de traçar um diagnóstico das anomalias. $O$ método de inspeção na unidade residencial foi preponderantemente conduzido por exame visual das fissuras e trincas, dando enfoque à identificação de suas configurações típicas, e envolvendo também a coleta de medidas das aberturas com fissurômetro e verificação de profundidade por meio de análise semi-destrutiva. Diante das características coletadas durante a inspeção, se identificou que a maioria das fissuras e trincas tinham em comum o aspecto de configuração inclinada e propagação diagonal. Somado a essa particularidade, o diagnóstico das fissuras e trincas foi obtido em razão da unidade residencial estar situada exatamente em uma região de balanço da estrutura do edifício, o que causa descolamentos verticais e movimentações nos sistemas da unidade, sobretudo nas paredes diretamente apoiadas sobre o balanço.
\end{abstract}

Palavras-chave: fissuras e trincas; estrutura em balanço; flecha.

Abstract: Cracks in masonry systems is one of the main pathological manifestations affecting civil construction. The objective of the present work is to present a case study carried out in a residential unit, in which cracks were identified in ceramic brick masonry sealing systems, to trace a diagnosis of the anomalies. The inspection method in the residential unit was predominantly conducted by a visual technique of cracks, focusing on the identification of its typical configurations, and also involving the measurement of apertures with a fissurometer and depth verification through semidestructive analysis. Considering the characteristics collected during the inspection, it was identified that most of the cracks had in common the aspect of inclined configuration and diagonal propagation. Besides that, the diagnosis of cracks was based on the fact that the residential unit is situated exactly in a droplet region of the building structure, which causes vertical displacements and movements in the unit systems, especially in the walls directly supported on the droplet.

Keywords: cracks; balance sheet structure; arrow. 
NASCIMENTO, R.S.; CICUTO, B. G. P. FISSURAS E TRINCAS EM SISTEMA DE ALVENARIA DE VEDAÇÃO: ESTUDO DE CASO EM UNIDADE RESIDENCIAL. $4^{\circ}$ Simpósio Paranaense de Patologia das Construções (40 SPPC), artigo 4SPPC154, pp. 491 - 503, 2019. DOI: 10.4322/2526-7248.071

\section{Introdução}

Dentre as manifestações patológicas que afetam as obras de construção civil, a abertura de fissuras e trincas, tanto em sistemas estruturais quanto em sistemas de vedação, se destacam por ser um dos problemas mais incidentes e com maior potencial de risco de ocasionar outros processos de degradação.

Brandão [1] aponta que mais da metade das residências unifamiliares possuem incidência de processos patológicos e que, tratando-se do sistema de vedação (parede), 69\% dos danos são em forma de fissuras.

Tendo em vista a recorrência dessa manifestação patológica assim como as possíveis consequências de sua formação para a edificação, como abertura facilitada para ingresso de agentes agressivos e infiltração de água, se faz necessário estudo a respeito de suas características e causas de origem, monitoramento e reparo adequado.

Dentro desse contexto, neste artigo será apresentado um estudo de caso conduzido em uma unidade residencial localizada na cidade de Brasília, na qual foram identificadas fissuras e trincas. O trabalho objetivou o diagnóstico de causas das anomalias.

\section{Objeto de estudo}

O objeto de estudo deste trabalho é uma unidade residencial modelo studio, situada em um edifício residencial com idade de aproximadamente 10 anos, composto por 02 subsolos, 01 pavimento térreo destinado à função comercial e edificado no modelo pilotis, 04 pavimentos tipo destinados à ocupação residencial e 01 cobertura de acesso privativo onde estão situadas as casas de máquinas e reservatórios.

\section{Metodologia}

A metodologia adotada para o desenvolvimento do trabalho foi divida em três etapas principais: 1 - Inspeção residencial; 2 - Estudo diagnóstico; 3 - Proposição de soluções técnicas. Cada etapa é descrita a seguir e ilustradas no fluxograma adiante (Figura 1).

O desenvolvimento do trabalho se fundamentou em diretrizes e conceitos da Norma de Inspeção Predial do Instituto Nacional de Perícia e Engenharia - IBAPE [2]. Dentro do contexto normativo, atribuiu-se ao presente trabalho NíVEL 1 de Inspeção Predial em função da baixa complexidade dos métodos de inspeção adotados.

Os dados coletados durante a inspeção na unidade foram reunidos e avaliados para o desenvolvimento de um estudo diagnóstico das anomalias no sentido de definir suas prováveis causas e origens e, sobretudo a fim de orientar os proprietários do imóvel na adoção das medidas de manutenção corretiva, propondo as soluções de tratamento mais apropriadas a cada caso. 
NASCIMENTO, R.S.; CICUTO, B. G. P. FISSURAS E TRINCAS EM SISTEMA DE ALVENARIA DE VEDAÇÃO: ESTUDO DE CASO EM UNIDADE RESIDENCIAL. $4^{\circ}$ Simpósio Paranaense de Patologia das Construções (40 SPPC), artigo 4SPPC154, pp. $491-503$, 2019. DOI: $10.4322 / 2526-7248.071$

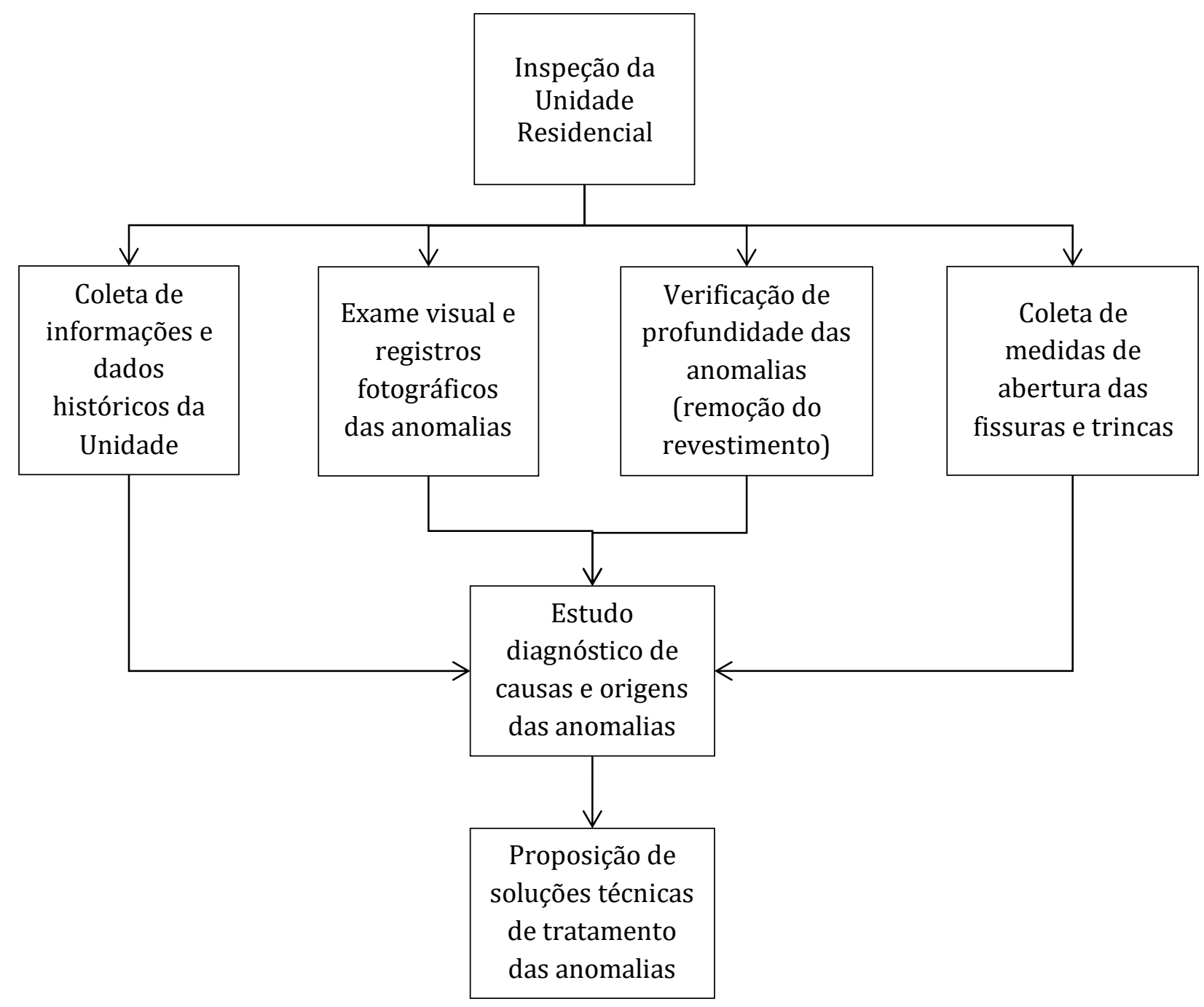

Figura 1: Metodologia de trabalho

\section{Inspeção residencial}

O primeiro passo da inspeção realizada na unidade foi o exame visual das anomalias que constituem objeto de estudo. Na sequência se procedeu à verificação de profundidade das anomalias por meio de análise semi-destrutiva com remoção do revestimento argamassado. Os dados coletados na inspeção são apresentados a seguir.

A primeira etapa do trabalho foi caracterizada pelas atividades de inspeção dentro da residência, com enfoque nas anomalias que constituíram objeto de estudo. O primeiro passo da inspeção foi a coleta de algumas informações históricas da unidade, fornecidas pela proprietária do imóvel, para composição de anamnese.

Na sequência as fissuras e trincas foram inspecionadas através de exame visual para identificação de suas configurações, complementando com registro de imagens e coleta de medidas de abertura. Em seguida se procedeu à verificação de profundidade máxima das anomalias por meio de análise semi-destrutitva com remoção parcial do revestimento argamassado. 
NASCIMENTO, R.S.; CICUTO, B. G. P. FISSURAS E TRINCAS EM SISTEMA DE ALVENARIA DE VEDAÇÃO: ESTUDO DE CASO EM UNIDADE RESIDENCIAL. $4^{\circ}$ Simpósio Paranaense de Patologia das Construções (40 SPPC), artigo 4SPPC154, pp. 491 - 503, 2019. DOI: $10.4322 / 2526-7248.071$

Os instrumentos e equipamentos usados para as atividades de inspeção in loco foram: máquina fotográfica semi-profissional para registro de imagens e fissurômetro para medida de abertura das anomalias. Para remoção da camada de revestimento foram usadas ferramentas manuais (talhadeira e marrete).

\subsection{Exame Visual}

Durante essa etapa as anomalias foram examinadas visualmente para identificação de suas configurações (origem, inclinação de propagação e largura de abertura), inclusive efetuando a coleta das medidas de abertura com o fissurômetro, objetivando a produção de diagnóstico de prováveis causas e origens. Para fins de orientação, foi atribuída uma identificação para as paredes divisórias do imóvel a fim de referenciar as anomalias conforme sua localização (Figura 2).

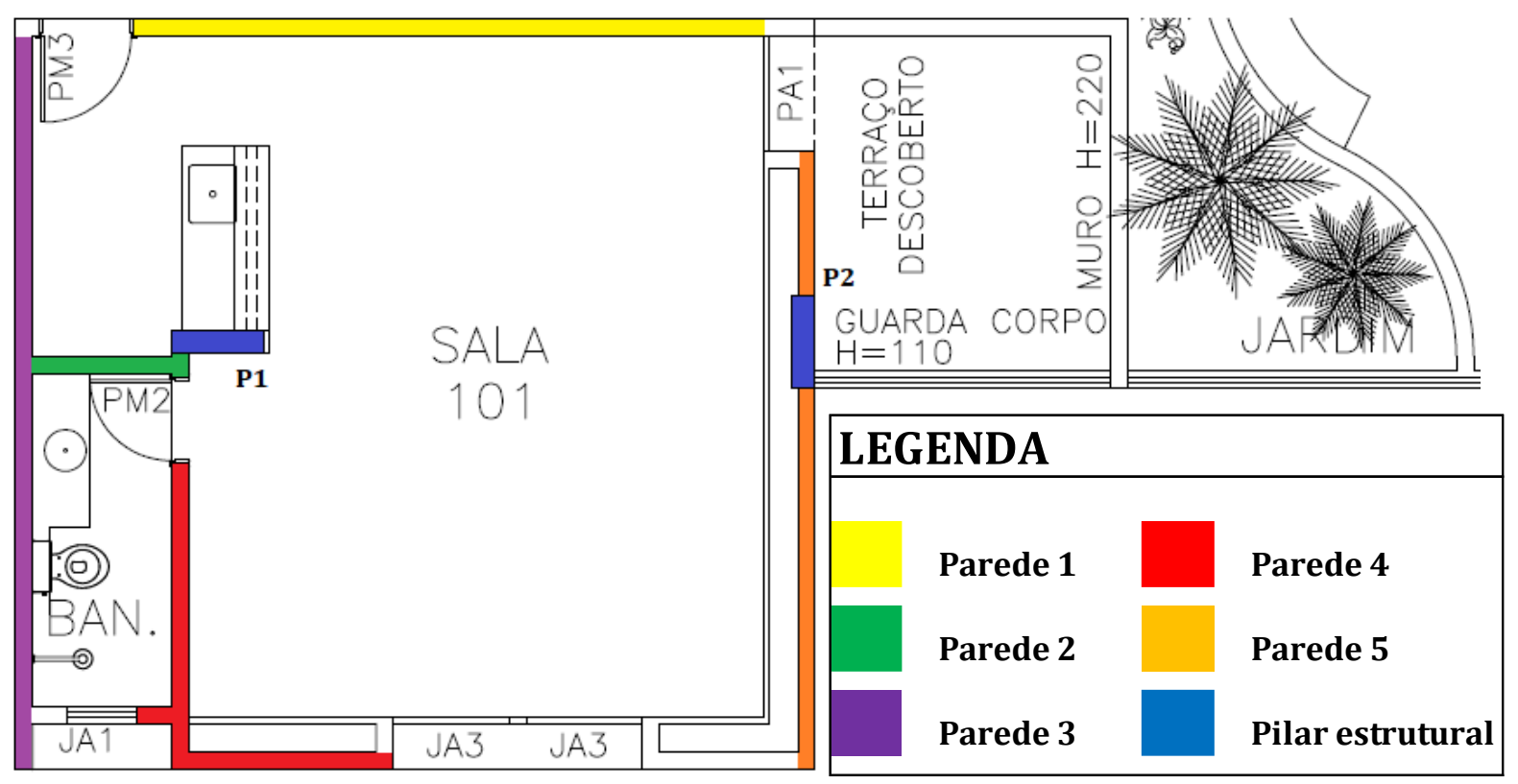

Figura 2: Planta da unidade residencial

$\mathrm{Na}$ parede 1 havia trincas paralelas, de configuração inclinada, propagadas da extremidade inferior da parede até a extremidade do revestimento de gesso do teto (Figura 3).

Na Parede 2, que divide a cozinha e o banheiro, havia fissuras e de aspecto similar, com configuração inclinada (Figura 4).

Na parede 3, que é perpendicular à parede 2, pela vista da cozinha, também foram identificadas fissuras próximas ao fogão. Observa-se que as fissuras seguem o mesmo aspecto das demais, também com configuração inclinada (Figura 5).

$\mathrm{Na}$ parede 4, que divide o quarto e o banheiro, foi identificada uma trinca de maior magnitude, que apresenta a mesma configuração inclinada e propagação longitudinal (Figura 6). 
NASCIMENTO, R.S.; CICUTO, B. G. P. FISSURAS E TRINCAS EM SISTEMA DE ALVENARIA DE VEDAÇÃO: ESTUDO DE CASO EM UNIDADE RESIDENCIAL. $4^{\circ}$ Simpósio Paranaense de Patologia das Construções (40 SPPC), artigo 4SPPC154, pp. 491 - 503, 2019. DOI: 10.4322/2526-7248.071
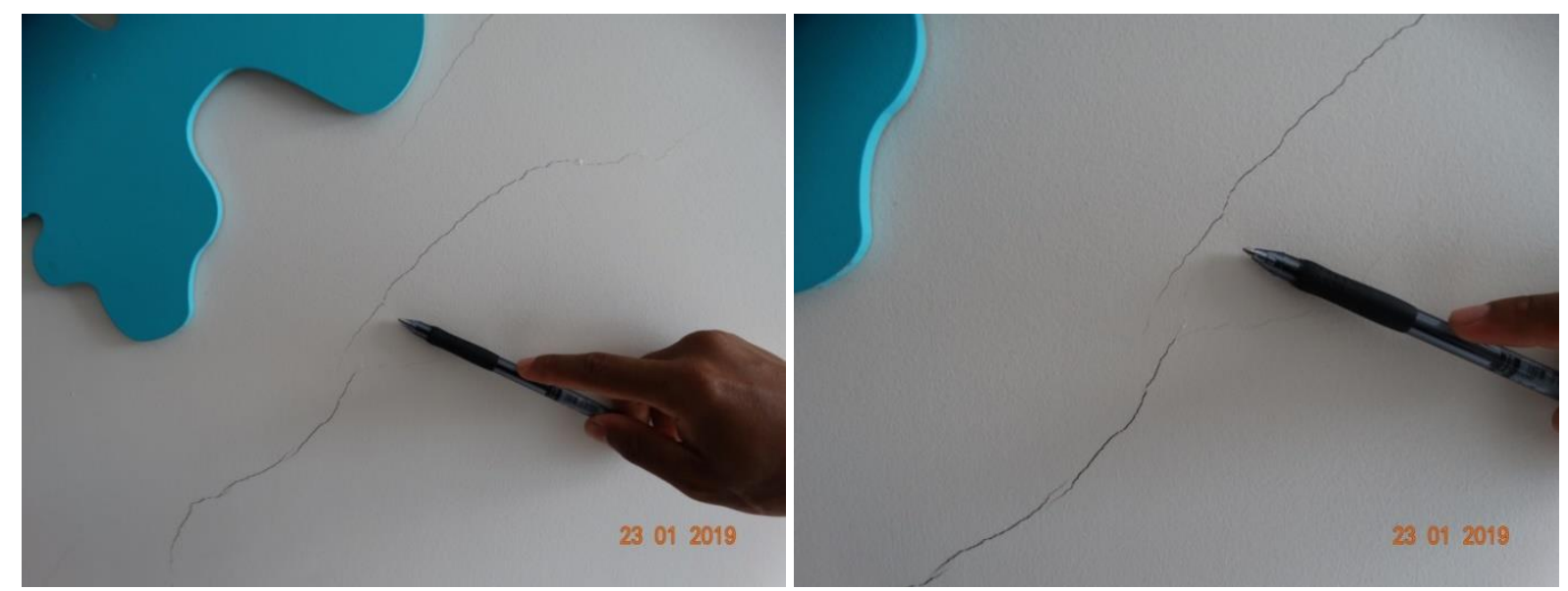

Figura 3: Fissura na Parede 1 (vista da sala)
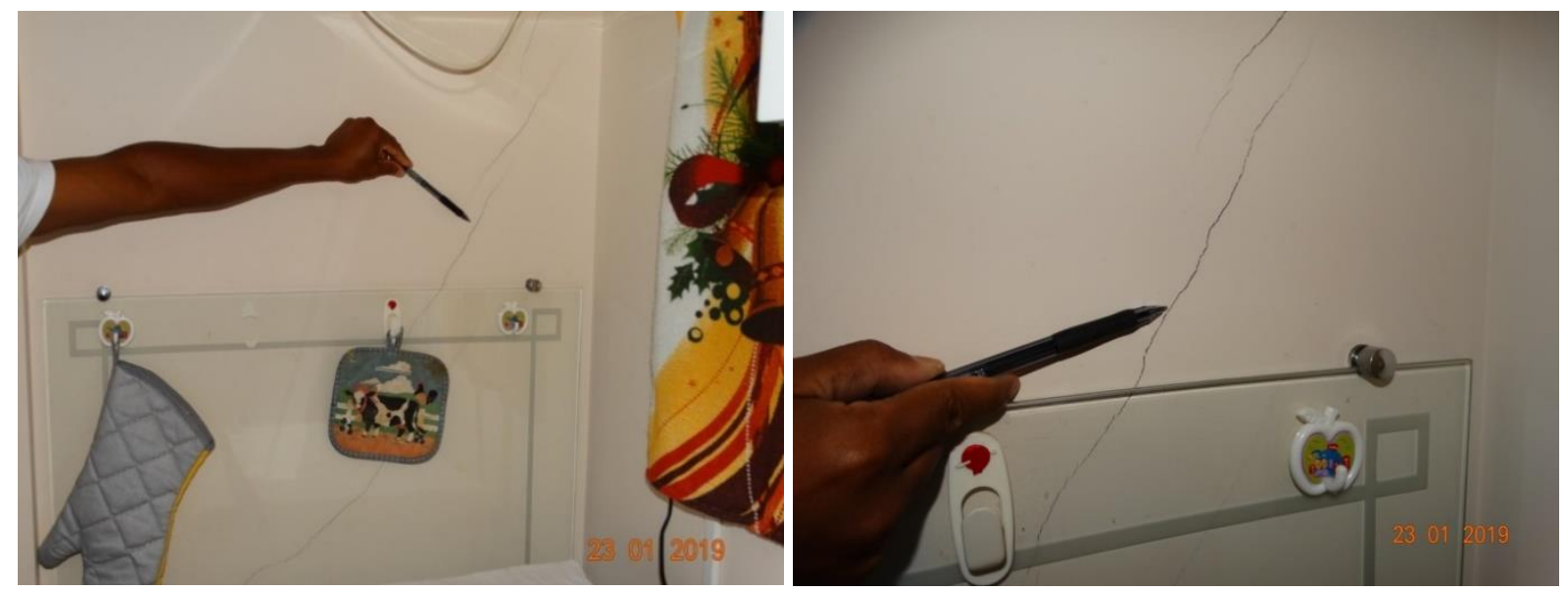

Figura 4: Fissura na Parede 2 (vista da cozinha)
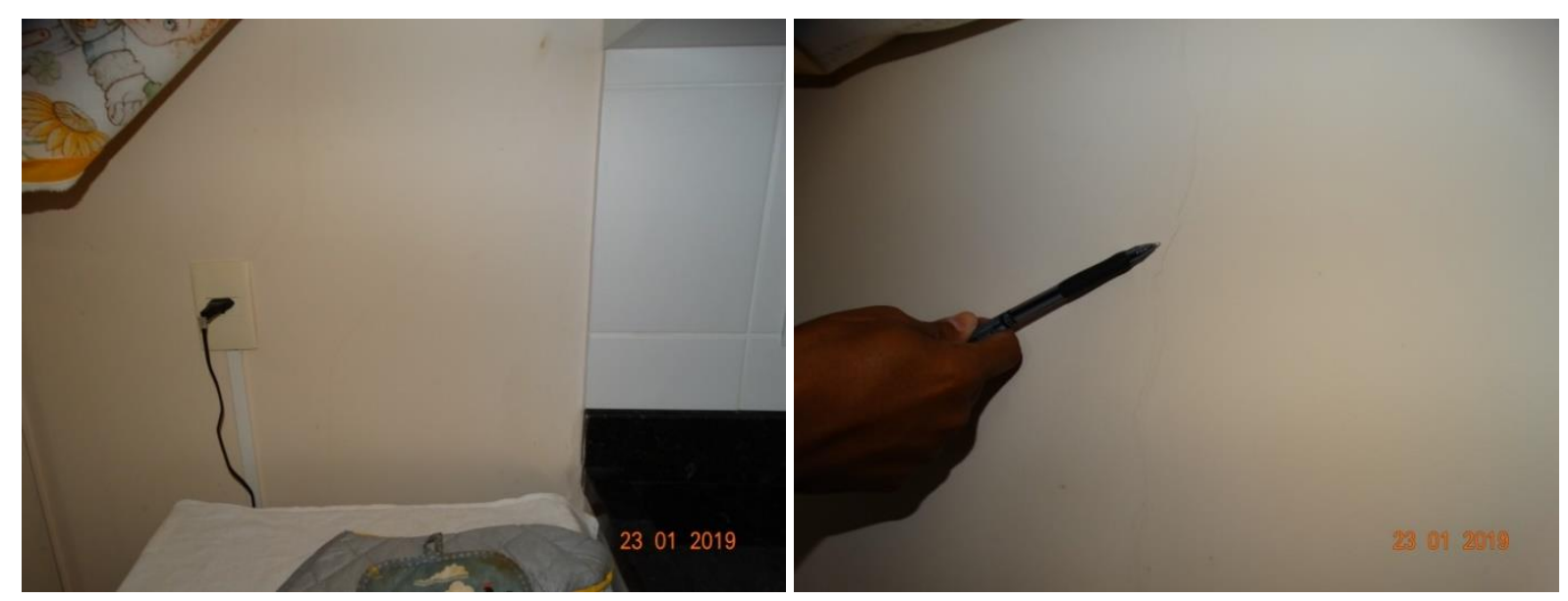

Figura 5: Fissuras inclinadas na Parede 3 (vista da cozinha) 

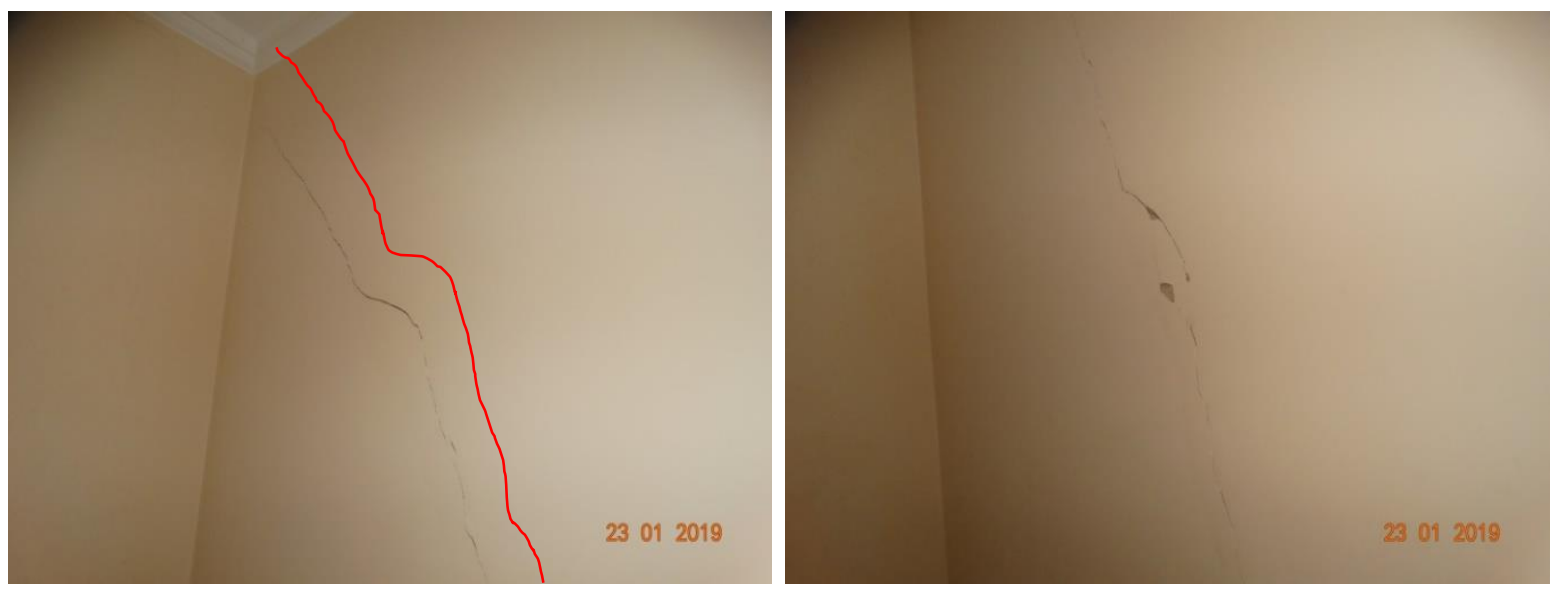

Figura 6: Trinca inclinada na Parede 4

Pelo interior do banheiro se observou que também há manifestação de uma trinca na face oposta da Parede 4 (Figura 7). Novamente, a trinca apresenta o mesmo aspecto das anomalias citadas acima, com configuração inclinada, e se propaga da extremidade inferior da parede, próximo ao piso, até a extremidade superior.

No revestimento cerâmico da Parede 2, quando vista pelo interior do banheiro, ou seja, em sua face oposta, também foram identificadas trincas de configuração inclinada (Figura 8).
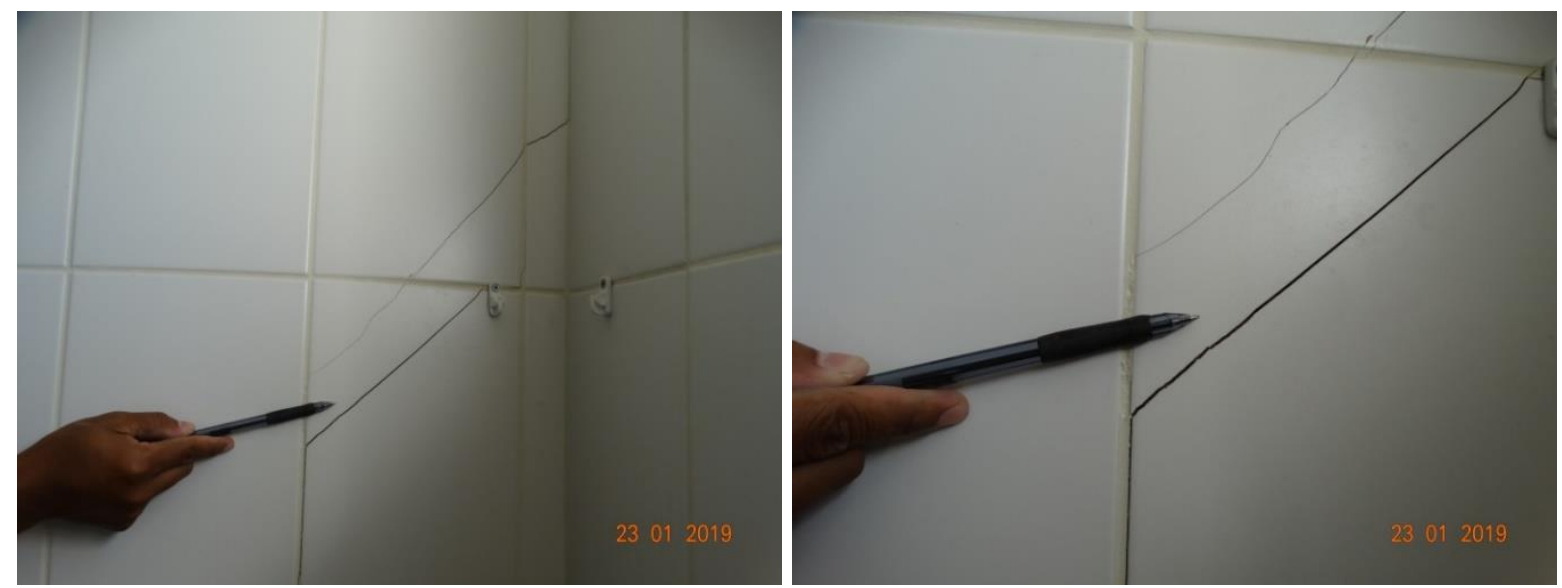

Figura 7: Detalhe da Trinca inclinada na Parede 4 (vista do banheiro)

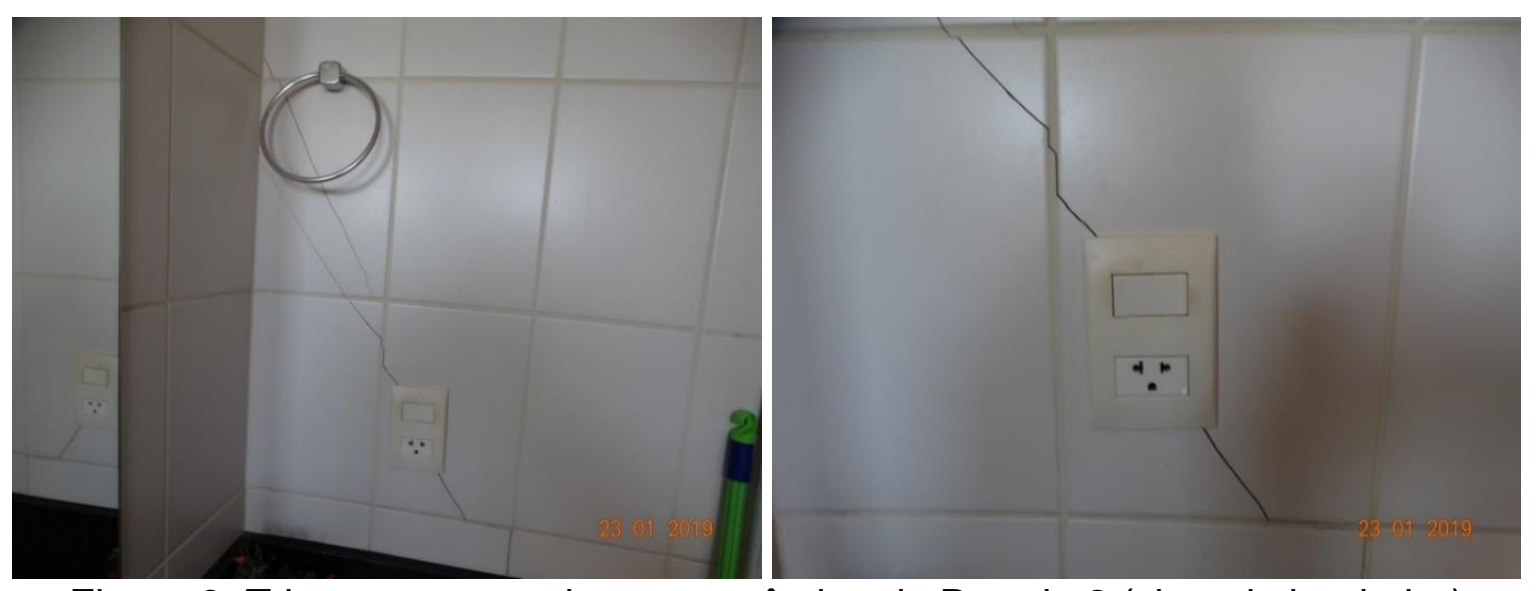

Figura 8: Trincas no revestimento cerâmico da Parede 2 (vista do banheiro) 
NASCIMENTO, R.S.; CICUTO, B. G. P. FISSURAS E TRINCAS EM SISTEMA DE ALVENARIA DE VEDAÇÃO: ESTUDO DE CASO EM UNIDADE RESIDENCIAL. $4^{\circ}$ Simpósio Paranaense de Patologia das Construções (40 SPPC), artigo 4SPPC154, pp. 491 - 503, 2019. DOI: $10.4322 / 2526-7248.071$

\subsection{Coleta de medida de abertura das fissuras}

Dando sequência à inspeção, após o exame visual preliminar, as fissuras e trincas foram medidas com o fissurômetro para determinar suas respectivas larguras de abertura.

A fissura identificada na Parede 1 (vista da sala) tinha abertura variando aproximadamente no intervalo de 0,3 à 0,4 mm (Figura 9).
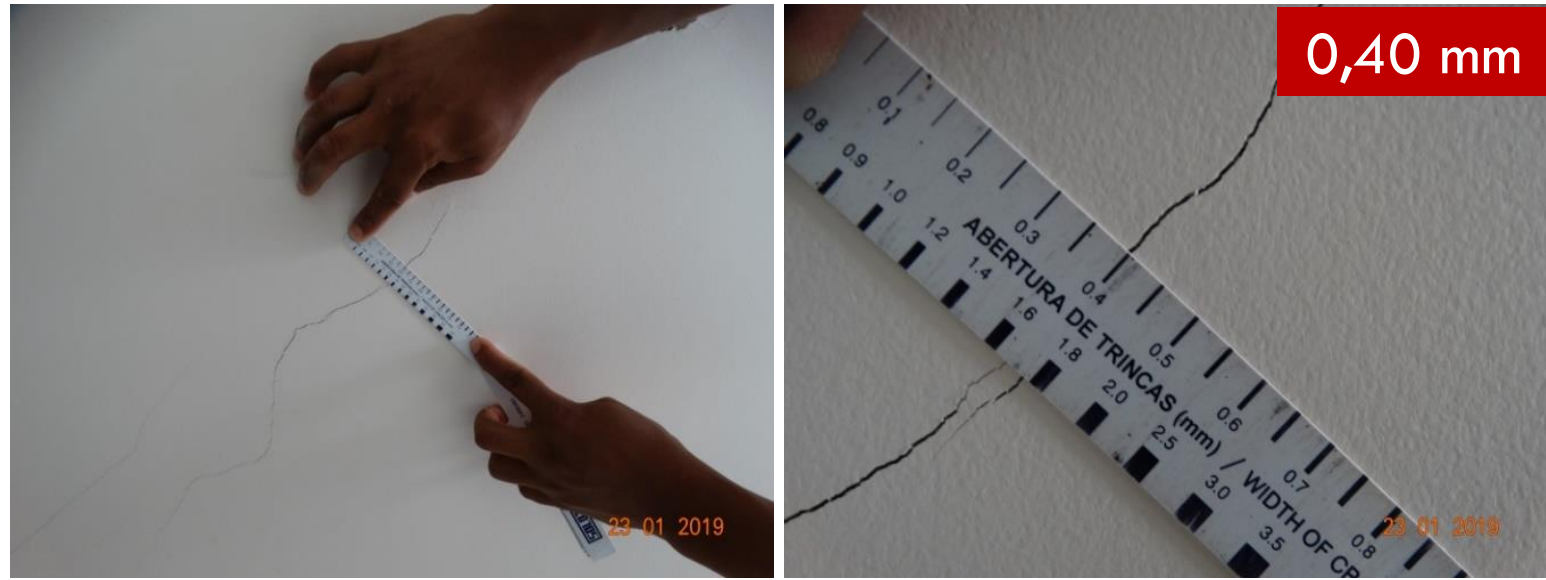

Figura 9: Fissura na Parede 1 (vista da sala), medida com 0,40 mm de abertura.

A fissura na Parede 2 (vista da cozinha) foi medida com 0,70 mm (Figura 10).

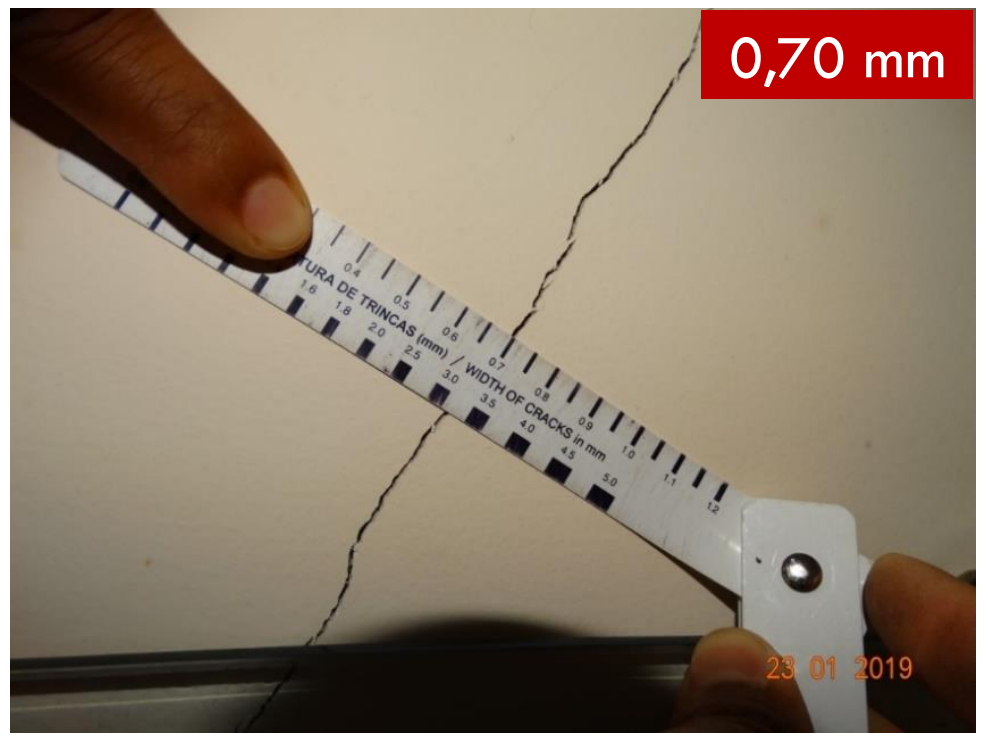

Figura 10: Fissura na Parede 2 (vista da cozinha) medida com 0,70 mm de abertura.

Dentre as anomalias identificadas, a trinca na Parede 3, medida pelo quarto, era a de maior magnitude com relação à largura de abertura, variando no intervalo de $0,70 \mathrm{~mm}$ à $1,80 \mathrm{~mm}$ (Figura 11). Pela face no interior do banheiro, a trinca na Parede 3 foi medida com 1,0 mm (Figura 12). 

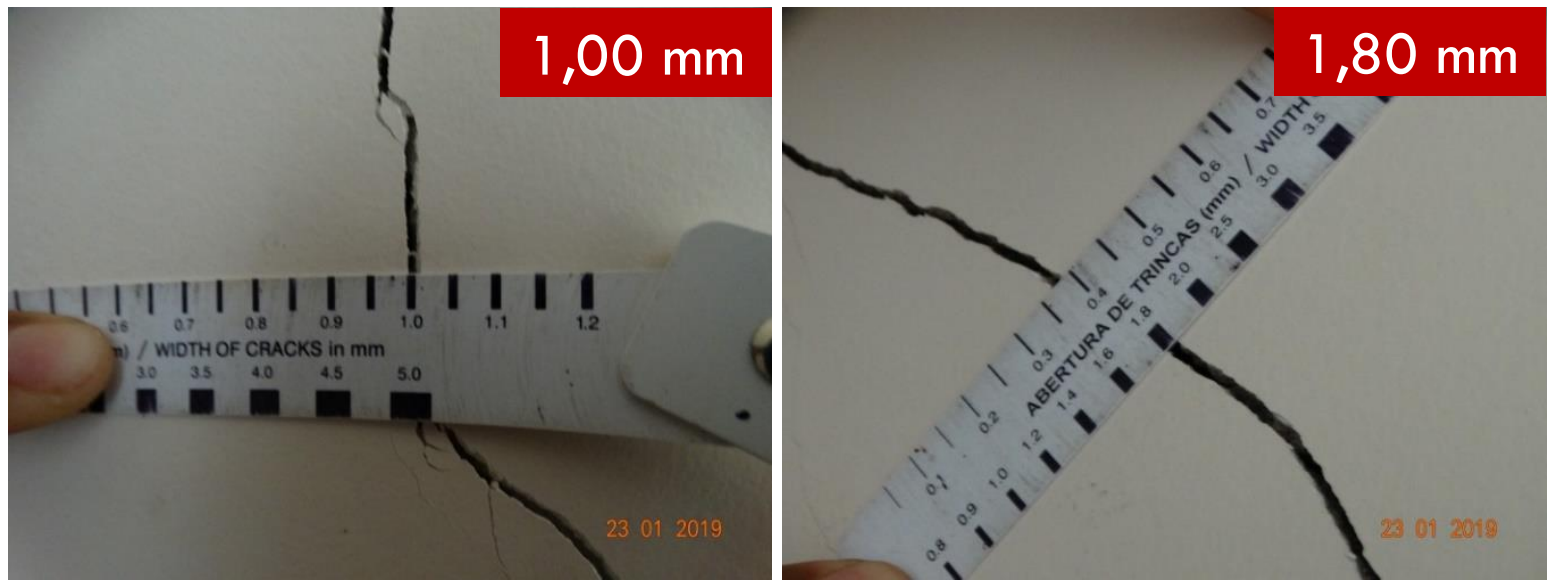

Figura 11 - Coleta de medidas da trinca na Parede 4 (vista do quarto. (a) Abertura de $1,0 \mathrm{~mm}$. (b) Abertura de 1,8 mm.
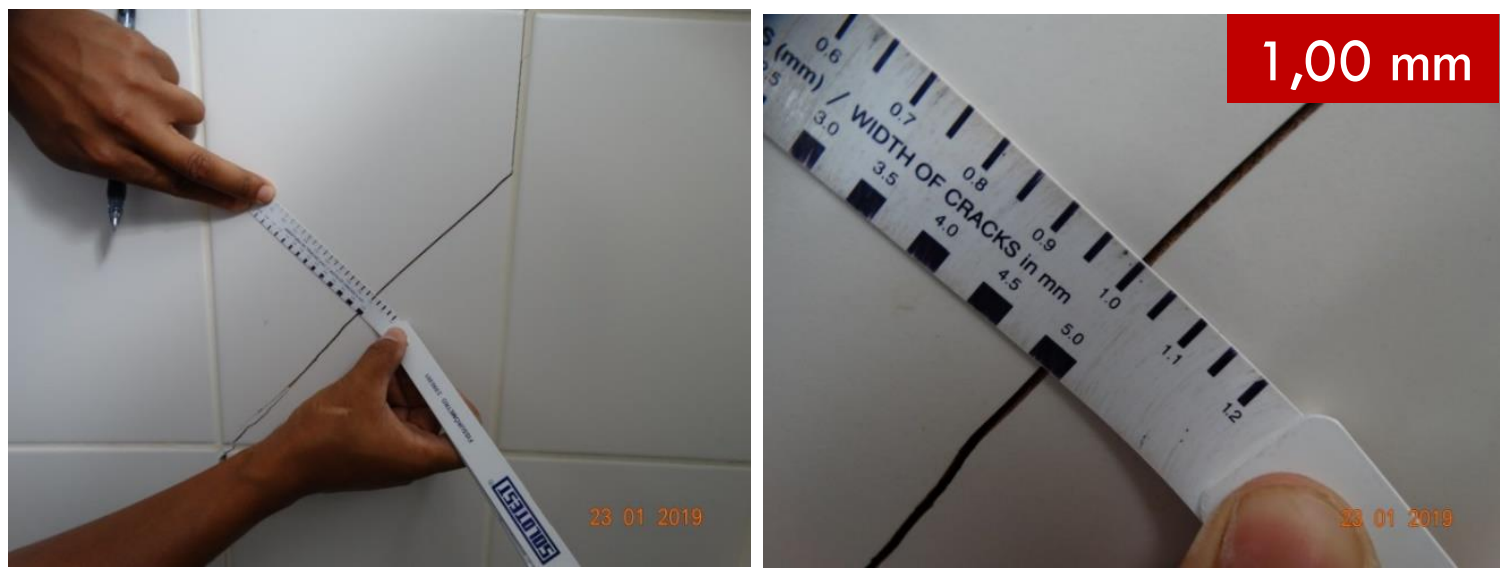

Figura 12 - Trinca na Parede 4 (vista do banheiro) medida com 1,0 mm de abertura.

Seguindo um critério comumente adotado por profissionais da área de engenharia diagnóstica, as anomalias identificadas no estudo de caso foram classificadas em fissuras ou trincas conforme o intervalo de medidas coletadas com o fissurômetro (Tabela 1).

Tabela 1: Classificação das anomalias de acordo com o intervalo de abertura

\begin{tabular}{l|l|l|l}
\hline Localização da anomalia & Perspectiva & $\begin{array}{l}\text { Intervalo de } \\
\text { abertura }(\mathbf{m m})\end{array}$ & Classificação \\
\hline Parede 1 & Sala & $0,30-0,40$ & Fissura \\
\hline Parede 2 & Cozinha & 0,70 & Trinca \\
\hline Parede 4 & Quarto & $0,70-1,80$ & Trinca/Rachadura \\
\hline Parede 4 & Banheiro & $1,0-1,15$ & Trinca \\
\hline
\end{tabular}


NASCIMENTO, R.S.; CICUTO, B. G. P. FISSURAS E TRINCAS EM SISTEMA DE ALVENARIA DE VEDAÇÃO: ESTUDO DE CASO EM UNIDADE RESIDENCIAL. $4^{\circ}$ Simpósio Paranaense de Patologia das Construções (40 SPPC), artigo 4SPPC154, pp. 491 - 503, 2019. DOI: 10.4322/2526-7248.071

\subsection{Verificação de profundidade das fissuras}

Para a escolha da técnica de tratamento mais apropriada à cada situação de fissura ou trinca, um dos aspectos fundamentais que deve ser determinado são as camadas do sistema que estão sendo atingidas.

O passo seguinte da inspeção foi a medida da profundidade máxima das fissuras e trincas identificadas. Dado que as trincas localizadas na Parede 1 e na Parede 4 foram medidas com as maiores aberturas de largura, foram selecionadas como manifestações amostrais para a verificação de profundidade. Para tanto, nos pontos onde foram coletadas as medidas de largura das duas trincas se executou uma abertura no revestimento, removendo-o com auxílio de ferramentas manuais.

Com a remoção do revestimento na região da trinca na Parede 1 (vista da sala) se identificou que a anomalia é superficial, ou seja, está limitada na camada de argamassa e os blocos cerâmicos se encontram conservados. É possível observar na Figura 13 que a fissura não se propagou para o interior do revestimento.
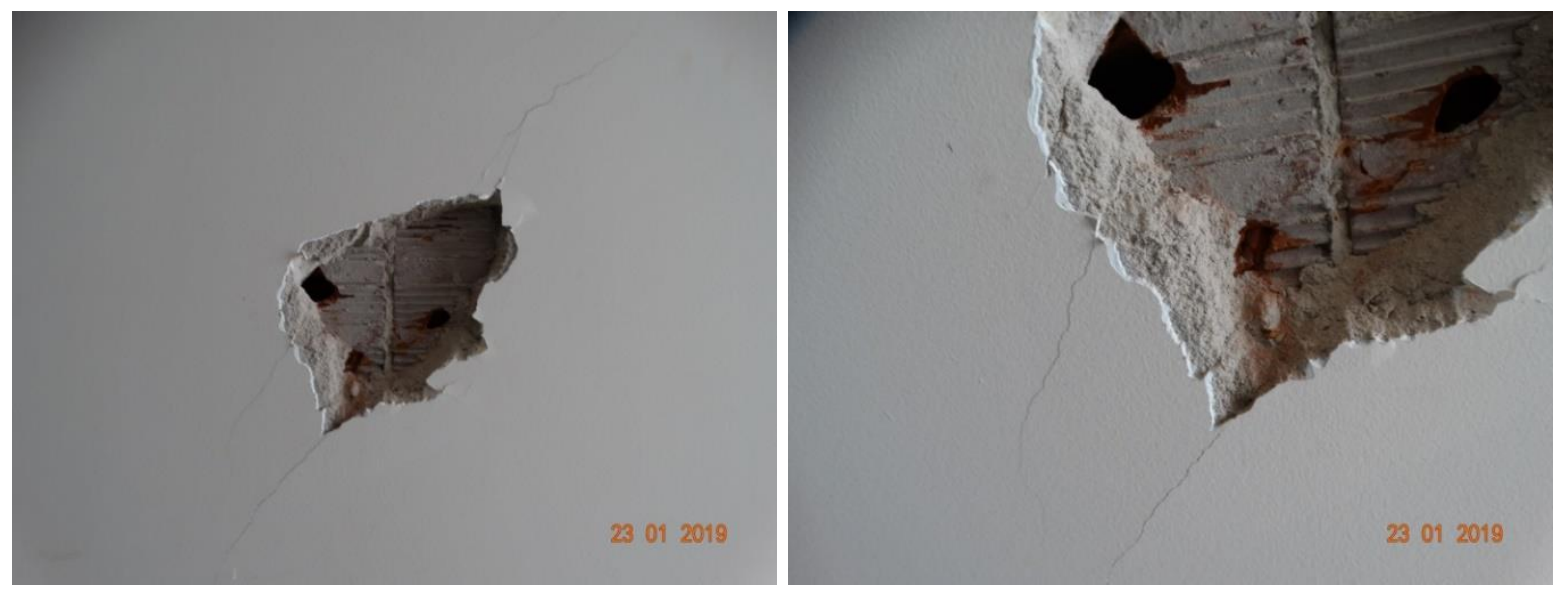

Figura 13: Detalhe da trinca na Parede 1 limitada na superfície do revestimento

Repetindo o mesmo procedimento na Parede 4, na face voltada para o quarto, após a remoção do revestimento se verificou que a trinca atingiu a profundidade da alvenaria, pois os blocos cerâmicos também estavam trincados (Figura 14).
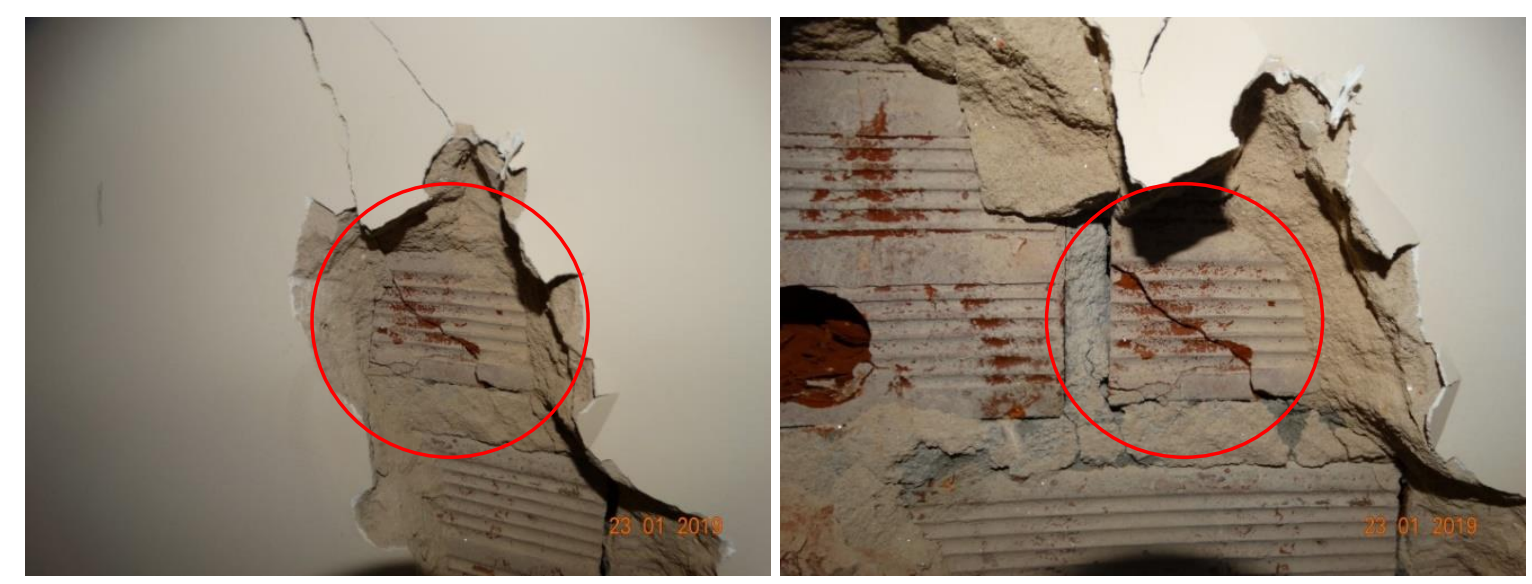

Figura 14: Bloco cerâmico trincado na Parede 4 (vista do quarto) 
NASCIMENTO, R.S.; CICUTO, B. G. P. FISSURAS E TRINCAS EM SISTEMA DE ALVENARIA DE VEDAÇÃO: ESTUDO DE CASO EM UNIDADE RESIDENCIAL. $4^{\circ}$ Simpósio Paranaense de Patologia das Construções (40 SPPC), artigo 4SPPC154, pp. 491 - 503, 2019. DOI: 10.4322/2526-7248.071

\section{Avaliação diagnóstica}

Nessa seção será apresentada a análise das causas e origens das manifestações patológica assim como o grau de risco.

\subsection{Análise e causas}

Pôde-se observar que, com exceção das fissuras verticais na Parede 5 , todas as demais trincas têm em comum o aspecto de configuração inclinada, ou seja, se propagam diagonalmente. Segundo autores e profissionais de destaque que atuam na área de patologias da construção civil e engenharia diagnostica - dentre eles Thomaz (1989) [3] -, no caso de paredes de alvenaria apoiadas em estruturas em balanço, a movimentação da estrutura na região do balanço pode gerar fissuras inclinadas na parede e/ou fissuras verticais ou horizontais por destacamento entre a parede e a estrutura, conforme exemplo ilustrativo na Figura 15 abaixo.
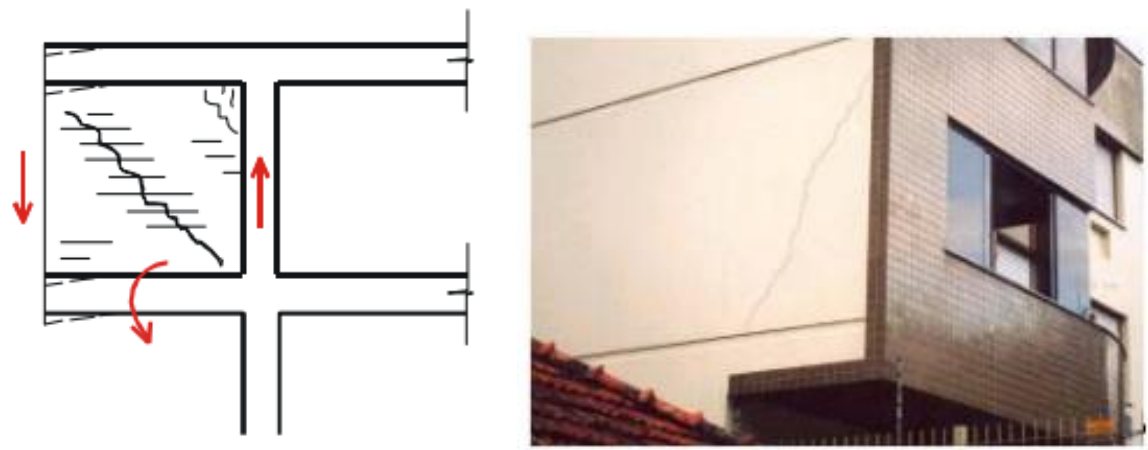

Figura 15: Fissura inclinada em parede de alvenaria por deflexão do balanço. (a) Fonte: Thomas, 1989. (b) Fonte: Magalhães, 2004.

O autor [3] acrescenta que essa manifestação patológica é um problema particularmente típico de edifícios sobre pilotis, onde o balanço é intencionalmente utilizado para alívio das solicitações de momento positivo.

Dentro desse contexto, é fundamental observar que o modelo de construção do Edifício onde está situada a unidade residencial que constituiu este estudo de caso é caracterizado pela edificação em pilotis, que proporciona circulação livre no pavimento térreo, e estrutura em balanço, em que há um avanço da projeção do prédio em relação ao alinhamento dos pilares.

Ressalta-se que a unidade está situada exatamente em uma das regiões do Bloco onde há balanço da estrutura (Figura 16). Logo, a posição do imóvel o torna mais propício ao surgimento de fissuras e trincas oriundas de deformações de estruturas em balanço, o que justifica as anomalias identificadas. Inclusive, é válido notar que a trinca de maior magnitude, medida com 1,8 mm de abertura máxima, está justamente localizada na parede que está apoiada sobre o balanço, o onde o efeito da flecha é mais intenso por estar mais próximo à extremidade da estrutura. 


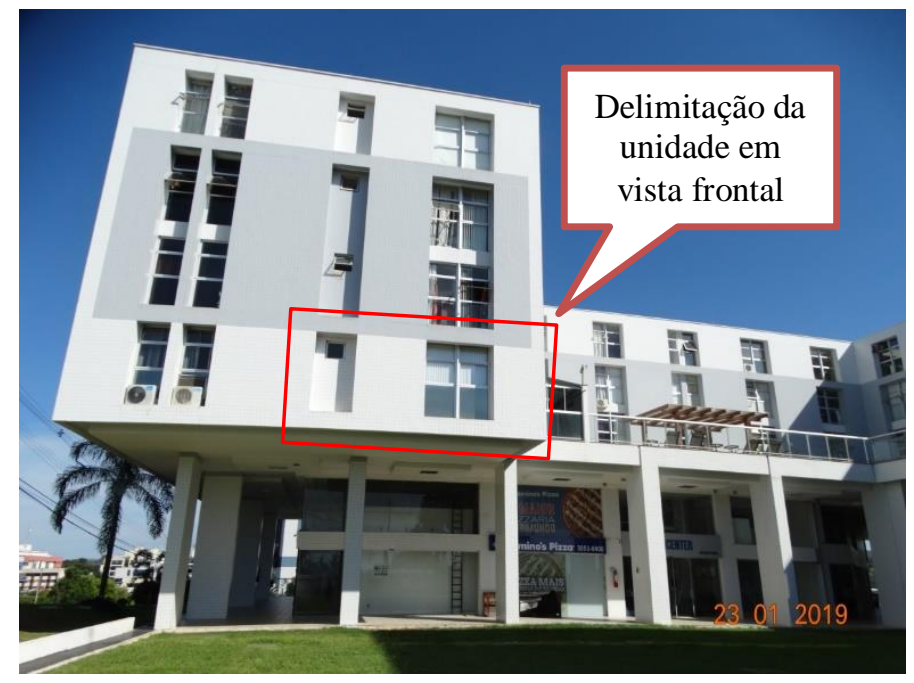

Figura 16 - Vista frontal da localização da unidade em estudo

Thomaz (1989) [3] também explica que, lajes em balanço, quando recebem carga, tendem a ser mais flexíveis que lajes totalmente apoiadas. Ocorre que, a falta de rigidez da estrutura provoca o surgimento de grandes descolamentos verticais " $\Delta$ " (Figura 17) em função da deformação lenta do concreto, denominada fluência, o que favorece a abertura de fissuras inclinadas nas alvenarias.
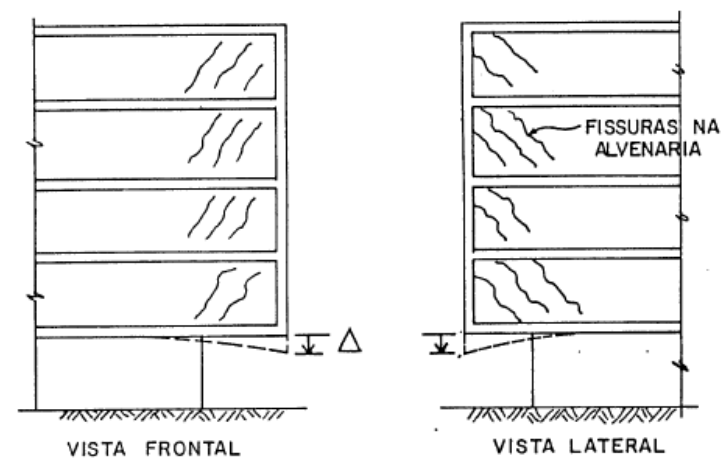

Figura 17: Exemplo ilustrativo de descolamento vertical de estrutura em balanço e surgimento de fissuras na alvenaria [3]

É importante esclarecer que a NBR 6118 (2014) [4] estabelece limites máximos admissíveis para o descolamento vertical (flecha) de estruturas convencionais, e em balanço. Para este estudo de caso, não foi aplicado teste de prova de carga para determinação do descolamento da estrutural. Logo, não se sabe se o descolamento vertical do balanço excede o limite máximo aceitável pela NBR 6118 ou não. Contudo, independente do descolamento ser, ou não, excessivo em relação ao limite máximo admitido pela norma, as movimentações conferidas podem provocar a abertura de fissuras e trincas em elementos de alvenaria de fechamento.

Inclusive, acerca dos efeitos de flechas em elementos não estruturais, como alvenarias de vedação, na norma é comentado que deslocamentos estruturais podem ocasionar o mau funcionamento de elementos que, apesar de não fazerem parte da estrutura, estão a ela ligados. Embora a movimentação ocorra na estrutura de 
NASCIMENTO, R.S.; CICUTO, B. G. P. FISSURAS E TRINCAS EM SISTEMA DE ALVENARIA DE VEDAÇÃO: ESTUDO DE CASO EM UNIDADE RESIDENCIAL. $4^{\circ}$ Simpósio Paranaense de Patologia das Construções (40 SPPC), artigo 4SPPC154, pp. $491-503$, 2019. DOI: $10.4322 / 2526-7248.071$

concreto armado, as deflexões dos componentes estruturais introduzem tensões nos sistemas de fechamento que, em função da natureza de seus materiais constituintes (bloco de alvenaria, revestimento de argamassa e pintura) e da própria intensidade da movimentação, podem causar abertura de fissuras e trincas, caso não sejam absorvidas, ou seja, sempre que houver incompatibilidade entre as solicitações impostas e as admitidas pelo sistema. Isso justifica o surgimento de fissuras e trincas mesmo nas paredes mais afastadas do trecho que está apoiado sobre o balanço, conforme observado in loco.

\section{Proposição de soluções técnicas}

O processo de tratamento das fissuras e trincas identificadas no imóvel deve ser individualizado a depender da profundidade máxima da anomalia. Para tanto, foram propostas duas soluções alternativamente (A ou B).

A - Caso a fissura/trinca esteja limitada à camada de revestimento, a recuperação da anomalia poderá ser efetuada com selante flexível (poliuretano, silicone, etc.), seguindo os procedimentos explicados passo a passo a seguir.

1. Na abertura da trinca, seguindo toda sua extensão, deve ser aberto um sulco com formato de "vê", com aproximadamente $20 \mathrm{~mm}$ de largura e $10 \mathrm{~mm}$ de profundidade (Figura 18);
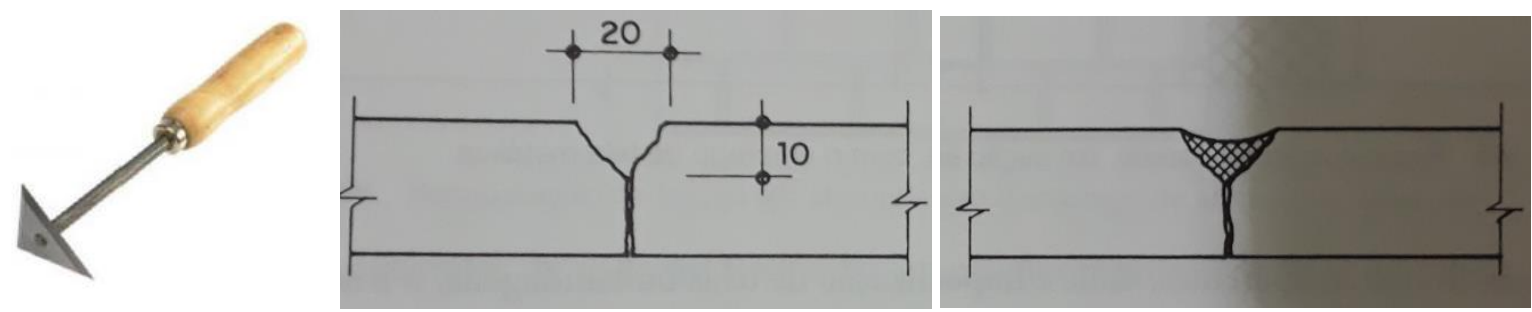

Figura 18 - Ferramenta "abre-trincas" e formato do sulco que deverá ser aberto

2. Limpeza do sulco para remoção dos resíduos aderidos (poeira e partículas soltas) e aplicação de fundo preparador, de acordo com a orientação do fabricante do material que será utilizado para preenchimento;

3. Aplicação de selante flexível monocomponente tixotrópico, à base de poliuretano, no sulco aberto;

4. Incorporação de telas metálicas, de náilon ou polipropileno,-- na superfície dos blocos cerâmicos - com transpasse na faixa de $15 \mathrm{~cm}$ para cada um dos lados da trinca.

5. Aplicação de chapisco de argamassa no traço 1:3 (cimento: areia) em volume;

6. Recomposição do revestimento com aplicação de argamassa com baixo módulo de deformação, traço 1:2:9 (cimento: cal: areia) em volume;

7. Pintura final de acabamento com aplicação de tinta elástica à base de resina acrílica ou poliuretânica.

B - Especificamente no caso das trincas que atingiram a camada de alvenaria, recomendou-se que também seja promovido tratamento dos blocos cerâmicos 
NASCIMENTO, R.S.; CICUTO, B. G. P. FISSURAS E TRINCAS EM SISTEMA DE ALVENARIA DE VEDAÇÃO: ESTUDO DE CASO EM UNIDADE RESIDENCIAL. $4^{\circ}$ Simpósio Paranaense de Patologia das Construções (40 SPPC), artigo 4SPPC154, pp. $491-503$, 2019. DOI: $10.4322 / 2526-7248.071$

trincados com aplicação de material selante flexível, seguido de costura da alvenaria no alinhamento da trinca, com colocação de barras de aço cruzadas em modelo $Z$.

Uma recomendação geral aplicável ao tratamento de fissuras e trincas originadas por esse motivo é que, durante os procedimentos a área da unidade que está apoiada sobre o trecho em balanço seja mantida com carregamento. Se a carga na laje em balanço for retirada para o procedimento de reparo, após o término do serviço as fissuram abrirão novamente, pois a laje volta a se deformar quando for recarregada.

\section{Conclusão}

Durante a inspeção conduzida neste estudo de caso foram identificadas fissuras e trincas, sobretudo de configuração inclinada, nos sistemas de vedação do imóvel. Reunindo os dados coletados in loco se desenvolveu um estudo diagnóstico a fim de determinar as causas e origens das anomalias identificadas. Os aspectos das anomalias identificadas e as características construtivas do edifício apontam que as fissuras e trincas inclinadas são de origem das movimentações causadas pelo descolamento da estrutura em balanço.

Não é cabível afirmar se os descolamentos do balanço são, ou não, excessivos em relação ao limite máximo permitido pela NBR 6118. Porém, deve ser considerado que, independente de sua amplitude, as flechas geram movimentações no sistema de alvenaria e, caso a intensidade da solicitação seja superior à admitida pelo sistema, ocorre a abertura de fissuras e trincas.

Diante do diagnóstico de causas e origens das anomalias, dentre outras particularidades, foram propostas as soluções de tratamento aplicáveis à cada caso. Contudo, adverte-se que, as manifestações patológicas foram causadas pela deflexão do balanço. Logo, mesmo após os serviços de reparo, as manifestações patológicas poderão surgir novamente, pois a estrutura permanece em deformação lenta (fluência) ao longo dos anos.

\section{Referências}

[1] BRANDÃO, R. M. L. Levantamento das manifestações patológicas nas edificações, com até cinco anos de idade, executadas no Estado de Goiás. 2007. 196 f. Dissertação (Mestrado em Engenharia) - Curso de Mestrado em Engenharia Civil, Escola de Engenharia Civil, Universidade Federal de Goiás, Goiânia, 2007

[2] THOMAZ, E. Trincas em edifícios: causas, prevenção e recuperação. São Paulo: Pini. Escola Politécnica da Universidade de São Paulo: Instituto de Pesquisas Tecnológicas, 1989.

[3] INSTITUTO BRASILEIRO DE AVALIAÇÕES E PERÍCIAS DE ENGENHARIA DE SÃO PAULO. Norma de Inspeção Predial, São Paulo, 2011.

[4] ASSOCIAÇÃO BRASILEIRA DE NORMAS TÉCNICAS. NBR 6118: Projeto de estruturas de concreto - Procedimento, Rio de Janeiro, 2014. 